Article

\title{
On the Growth Rate of Tribomaterial in Bovine Serum Lubricated Sliding Contacts
}

\author{
Alfons Fischer ${ }^{1,3, *}$, Daniel Stickel ${ }^{1}$, Christian Schoss ${ }^{1}$, Rob Bosman ${ }^{2}$ and Markus A. Wimmer ${ }^{3}$ \\ 1 Materials Science and Engineering, University of Duisburg-Essen, 47057 Duisburg, Germany; \\ daniel.stickel@uni-due.de (D.S.); christian.schoss@stud.uni-due.de (C.S.) \\ 2 Surface Technology and Tribology, University of Twente, 7500 AE Enschede, The Netherlands; \\ r.bosman@utwente.nl \\ 3 Department of Orthopedics, Rush University Medical Center, Chicago, IL 60612, USA; \\ markus_a_wimmer@rush.edu \\ * Correspondence: alfons.fischer@uni-due.de; Tel.: +49-203-379-4372; Fax: +49-203-379-4374
}

Academic Editors: Werner Oesterle and Ga Zhang

Received: 16 February 2016; Accepted: 5 May 2016; Published: 21 June 2016

\begin{abstract}
Considering total hip arthroplasty, so-called tribolayers (aka tribomaterial), consist of carbonaceous material from the periprosthetic joint fluid or bovine serum mixed with nanometer size metal and oxide wear particles. Currently, its growth sequence and rate are unknown. Thus, smooth surfaces of low-Carbon (LC-) vs. high-Carbon (HC-)CoCrMo (Cobalt-Chromium-Molybdenum) alloys have been worn in a conforming contact under bovine serum lubrication by means of a pin-on-ball wear tester. These tests were interrupted at certain numbers of cycles in order to weigh the specimens, characterize the topography, and investigate the wear appearances. In addition, after cleaning in ethanol and anionic detergent, before-and-after comparison rendered the weight of the tribomaterial. This revealed that, during run-in, the specimens gained weight by generating tribomaterial. Afterwards the loss of material surpassed the generation of new tribomaterial and a steady weight-loss was measured. Topography measurements were used as input data for contact mechanics calculations. Apparently the incipient, locally high contact stresses accelerated tribochemical reactions. After run-in, the contact situation changes and leads to a much smaller generation rate. This paper provides information about the growth sequence and rate of such tribomaterial formation. It further highlights the significance of highly localized contact stress as an important factor for tribomaterial generation.
\end{abstract}

Keywords: tribomaterial; bovine serum; sliding wear; metal-on-metal

\section{Introduction}

Until about three years ago, approximately one third of the more than 300,000 annually performed hip arthroplasties in the United States were made of self-mating cobalt-chromium $(\mathrm{CoCr})$ alloy bearing surfaces [1]. However, some of these metal-on-metal (MoM) devices failed at a high rate [2]. This was unexpected since such metal-on-metal hip joints have been used fairly well in clinical practice since the 1960s. Different risk factors of especially large diameter MoM bearings were identified while the exact mechanisms of failure are still not well understood [3-6]. Our own contribution to this discussion was that maybe one out of many aspects could be the influence of so-called "tribomaterial" $[7,8]$. Many papers of protein lubricated metal-on-metal sliding contacts in vivo and in vitro report on tribochemically generated layers [9-12]. These socalled tribofilms, aka tribomaterial, consist of carbonaceous material from the periprosthetic joint fluid mixed with nanometer size metal and oxide wear particles, while other constituents are still under investigation [13-15]. It should be mentioned here that the authors do not distinguish between adsorbed and lubricating tribofilms as some references do. According to the basics of the 3rd-body-model of $[16]$ in combination with $[17,18]$ 
the "tribomaterial" contains physisorbed, chemisorbed, as well as reaction layers at the surfaces together with the lubricating part further away from it. Due to the constant stirring of the tribomaterial by the high shear rates all constituents including the wear particles are mixed within each other forming a composite. Such nanostructured metal-organic composite is supposed to be much softer than the supporting metal surface. No hardness values have been reported yet, but the properties derived by atomic-force microscopy (AFM) measurements could only be described as "gooey". It is assumed that this tribomaterial acts as a boundary lubricant separating direct metal-metal contacts and is able to accommodate the high shear rates without a marked loss of matter. Thus, such tribosystems often display mild and ultra-mild sliding wear behavior. The term "ultra-mild" is not defined but generally understood as describing tribosystems with a steady-state linear wear rate being smaller than $10 \mathrm{~nm} / \mathrm{h}$. This is important to notice, because most laboratory test-rigs running under mild-sliding wear generate wear rates in the range of $\mu \mathrm{m} / \mathrm{h}$. In order to maintain such small wear rates-still being bigger than "zero" - the some 10 to $100 \mathrm{~nm}$ thin tribomaterial has to be generated and worn continuously. Still, neither growth sequence nor rate are known. This paper aims to elucidate growth sequence and rate during tribomaterial formation in an in vitro metal-on-metal conforming contact. It should highlight the significance of the local contact stresses for tribomaterial generation under ultra-mild sliding wear conditions. Because of the limited number of specimens and lack of statistical power, this contribution stays qualitative. Therefore, the aim of the study is limited to just point towards mechanisms and parameters, that have been overlooked and/or insufficiently acknowledged in the past and might be observed in more detail in the future.

\section{Materials and Methods}

\subsection{Material}

Cylindrical pins ( $\varphi 12 \mathrm{~mm}$ ) with concave ends (Figure 1, Table 1), and spherical heads (Figure 1, Table 1) were provided by gb Implantat-Technologie GmbH (Essen, Germany) and Mathys Orthopaedics (Bettlach, Switzerland), respectively. The pins were manufactured from a standard wrought low-Carbon CoCrMo alloy (LC CoCr28Mo6, DIN ISO 5832-12) containing $27.1 \mathrm{w} \% \mathrm{Cr}, 5.6 \mathrm{w} \%$ Mo, and $0.05 \mathrm{w} \%$ C. The standard HC-CoCr28Mo6 heads with $29.7 \mathrm{w} \% \mathrm{Cr}, 6.2 \mathrm{w} \% \mathrm{Mo}$, and $0.25 \mathrm{w} \% \mathrm{C}$ were taken from stock.
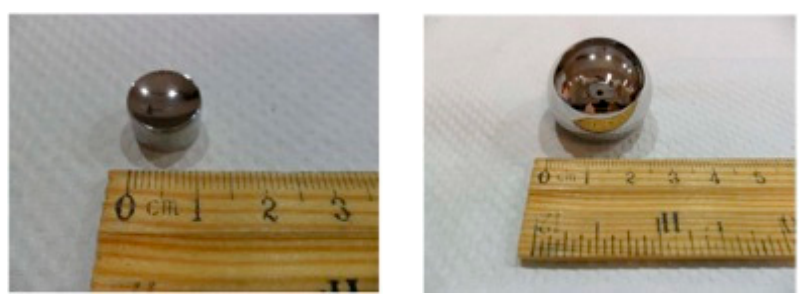

Figure 1. Concave Pin (left) and Head (right) manufactured from wrought low-Carbon (LC-) and high-Carbon (HC-)CoCrMo, respectively.

Table 1. Radii, Radial Clearance, Maximum Hertzian Contact Pressure before Wear Tests, and Roughness of the Specimens before the Wear Tests.

\begin{tabular}{cccccc}
\hline & Radius in $\mathbf{~ m m}$ & $\begin{array}{c}\text { Radial Clearance } \\
\text { in } \boldsymbol{\mu m}\end{array}$ & $\begin{array}{c}\text { Max. Hertzian } \\
\text { Contact Pressure } \\
\text { in MPa }\end{array}$ & $\boldsymbol{R}_{\mathbf{a}}$ in $\mu \mathbf{m}$ \\
\hline Ethanol + & Pin 1 (gb13) & 13.998 & 1 & $\approx 1$ & 0.006 \\
LiquiNox & Pin 2 (gb17) & 14.029 & 32 & 40 & 0.004 \\
Cleaning & Head 1 (20258) & 13.997 & - & - & 0.005 \\
Ethanol Cleaning & Pin 3 (gb09) & 14.025 & 32 & 40 & 0.005 \\
& Pin 4 (gb21) & 14.055 & 62 & -60 & 0.004 \\
& Head 2 (20257) & 13.993 & - & - & 0.005 \\
\hline
\end{tabular}


The radii before testing were assessed by means of a tactile coordinate measuring device (SmartScope Flash 250 Series, Optical Gaging Products Inc., Rochester, NY, USA).

\subsection{Laboratory Tribosystem and Analyses}

The tribosystem is displayed schematically in Figure 2 and Table 2. Polished concave pins of defined clearance are rotated and slid against a head under bovine serum lubrication (BCS, Sigma-Aldrich, St. Louis, MO, USA) at $37^{\circ} \mathrm{C}$ (Thermostat Julabo F25, Julabo Labortechnik GmbH, Seelbach, Germany) by means of a pin-on-ball wear test $[19,20]$. The interface motion is generated by sine-wave type axial oscillation of both the pins and the ball. By adjusting a $90^{\circ}$ phase shift between both amplitudes, elliptical displacement trajectories with crossing paths are generated. This concept allowed for an elliptical path at the center of the Hertzian contact area-similar to hip joints-with the relative speed varying between 25 and $35 \mathrm{~mm} / \mathrm{s}$ (Figure 2b, Table 2).

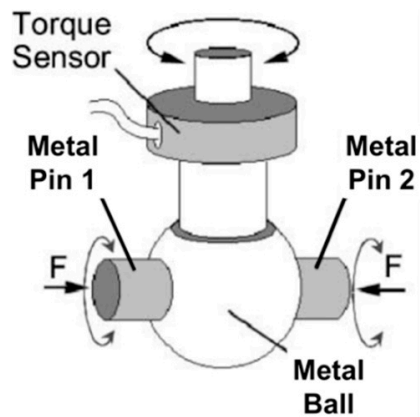

(a)

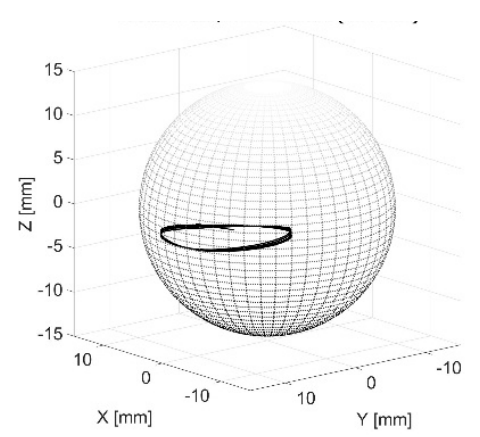

(b)

Figure 2. (a) Schematic of the Pin-on-Ball Wear Test; (b) Path of the Center of the Hertzian Contact Area on the Surface of a $28 \mathrm{~mm}$ Head during Five Cycles.

Table 2. Laboratory Tribosystem and its Loading Parameters.

\begin{tabular}{|c|c|c|}
\hline Main Elements & $\begin{array}{c}\text { Body } \\
\text { Counterbody } \\
\text { Interfacial Medium } \\
\text { Surrounding Medium and Temperature in }{ }^{\circ} \mathrm{C}\end{array}$ & $\begin{array}{c}\text { Head } \\
\text { Concave Pins } \\
\text { Bovine Calf Serum } \\
\text { Bovine Calf Serum at } 37^{\circ} \mathrm{C}\end{array}$ \\
\hline $\begin{array}{c}\text { Tribological } \\
\text { Stresses }\end{array}$ & $\begin{array}{c}\text { Type of Loading } \\
\text { Constant Normal Force in } \mathrm{N} \\
\text { Relative Velocity of the center of the Hertzian } \\
\text { contact in } \mathrm{mm} / \mathrm{s}(\text { at } 1 \mathrm{~Hz})(\text { s.a. Figure } 2 \mathrm{~b})\end{array}$ & $\begin{array}{l}\text { Multidirectional Sliding } \\
750 \\
25 \text { to } 35\end{array}$ \\
\hline Lubricant & BCS Solution, $\mathrm{pH}=7.6$ & $\begin{array}{c}588 \mathrm{~mL} \text { Bovine Calf Serum (BCS), } 3.7 \mathrm{~g} \mathrm{NaCl}, \\
82.4 \mathrm{mg} \text { EDTA, } 11.12 \mathrm{~g} \text { Trisaminomethane, } \\
412 \mathrm{~mL} \text { deionized water }\left(\mathrm{H}_{2} \mathrm{O}\right)\end{array}$ \\
\hline
\end{tabular}

The pneumatically applied normal force (ELPMT3M, Measurement Specialties Inc., Hampton, VA, USA) and the frictional forces (TRT-200, Transducer Techniques, Temecula, CA, USA) as well as the positions and rotations of pins and heads (R120LC, Measurement Specialties Inc., Hampton, VA, USA) were continuously measured and recorded (USB-1408FS, Measurement Computing Corporation, Norton, MA, USA, Matlab 2010b, The Mathworks, Natick, MA, USA).

The single test runs were interrupted after certain numbers of cycles from 100 to 500,000. After each test interval one group of samples were cleaned ultrasonically for $5 \mathrm{~min}$ in ethanol in order to remove loose debris from the surfaces. The other group was additionally cleaned ultrasonically for another $10 \mathrm{~min}$ in an anionic detergent (1\% LiquiNox solution, Alconox Inc., White Plains, NY, USA) in order to further remove any organic substance. The samples were dried after cleaning, immediately transferred into a closed chamber (XPert Weigh Box, Labconco, Kansas City, MO, USA) together with 
the scale (accuracy $10^{-4} \mathrm{~g}$; AX-204, Mettler Toledo, Giessen, Germany), and kept there before weighing for a minimum of $30 \mathrm{~min}$ for a complete temperature balance. The box itself was located inside a fully air-conditioned room in order to avoid any uptake of humidity. All samples were analyzed after each test interval by means of weighing, scanning white-light interferometry (topography by NewView 6300, Zygo Corporation, Middlefield, CT, USA) as well as scanning electron microscopy (JSM 6490LV, Jeol, Peabody, MA, USA with an energy-dispersive spectroscopy (EDS) system INCA x-sight, Oxford Instruments). The SEM was used in secondary-electron (SE) and/or in backscattered-electron (BSE) mode.

\subsection{Definition of Wear Rate}

In this paper the wear is displayed by either the weight loss in mg as measured or as ng/cycle. This change in weight will not be related to the wear path or test duration as it is usually done. The main reason doing so is that the authors believe that weight gain and weight loss are a better fit in the current study for the sake of clarity. Displaying the rate of growth and removal in $\mathrm{m} / \mathrm{m}$ or $\mathrm{nm} / \mathrm{h}$ would result in values spread over several orders of magnitude. This would require a logarithmic axis and prevent us from showing weight gain and loss in a single diagram.

\subsection{Modelling of Contact Conditions}

\subsubsection{Lubrication Regime}

The calculation of the lubrication regime is divided into the calculation of the minimum film thickness according to [21] and the Tallian-Parameter [22] as follows.

The minimum film thickness $h_{\min }$ :

$$
\frac{h_{\min }}{R}=2.8\left(\frac{\eta u}{E^{\prime} R}\right)^{0.65}\left(\frac{w}{E^{`} R^{2}}\right)^{-0.21}
$$

with $1 / R=1 / R_{1}-1 / R_{2}, E^{\prime}=E /\left(1-v^{2}\right), E=210 \mathrm{GPa}, v=0.3, w=750 \mathrm{~N}$ (standard body weight). While the center of the Hertzian contact moves by 25 to $35 \mathrm{~mm} / \mathrm{s}$ the entraining velocity at the outer rims of the rotating pins lies between 5 and $60 \mathrm{~mm} / \mathrm{s}$. Thus, the latter were used for $u$ to calculate the range of $\lambda$. If the viscosity $\eta$ of joint fluids is measured by means of a plate-on-plate rheometer it might drop from 10 and $0.01 \mathrm{~Pa}$ s [23,24], while for laboratory BCS it appears stable at $0.001 \mathrm{~Pa}$ s at high shear rates between 5000 to 30,000 1/s [25]. Still at smaller shear rates of about $10001 / \mathrm{s}$ BCS reveals viscosity levels between being ten times higher ranging from 0.021 to $0.026 \mathrm{~Pa}$ s and depending on the specific protein concentration [26]. Now within the range of relative velocities used in this paper it has been shown that the agglomeration of proteins at the inlet might even lead to a "gel-type" lubrication, which, in a first rough approach, could be modeled with a theoretical viscosity of $0.1 \mathrm{~Pa} \mathrm{~s}[27,28]$. However, [29] showed that this is mostly related to a ball-on-disc configuration, while in a conformal contact the lubricant film is formed mainly by hydrodynamic effects. Thus, at this point of research we follow the classical approach in order to roughly characterize our tribosystem.

The Tallian-Parameter was then calculated according to [21].

$$
\lambda=\frac{h_{\min }}{\sqrt{R_{a, 1}^{2}+R_{a, 2}^{2}}}
$$

Taking into account the ranges of measured relative velocities as well as viscosities from the above references $\lambda$ would range from about 0.004 to 0.1 with the $R_{a}$-values of the worn surfaces as will be shown later. Thus, this laboratory tribosystem is characterized mainly by boundary lubrication. 


\subsubsection{Dry Micro Contact Calculation}

The calculation of the real contact area was performed using a simplified micro linear elastic - perfectly plastic contact algorithm according to [30]. The limiting value for the micro contact pressure is set to the hardness of the softer material as will be shown later:

$$
\begin{gathered}
F_{N}=\int_{\Omega} p(x, y) d \Omega \\
h(x, y)=u_{z}(x, y)+h_{\text {ini }}(x, y)-\delta \geqslant 0 \\
p(x, y) \geqslant 0 \wedge p(x, y) \leqslant p_{\text {max }} \\
h(x, y) p(x, y)=0 \\
p(x, y)=0 \varnothing \Omega \\
h(x, y)=0 \subset \Omega
\end{gathered}
$$

With $h$ being the gap between the deformed contact bodies, $u_{z}$ the normal deflection of both surfaces, $h_{\text {ini }}$ the initial gap between the undeformed bodies and $\delta$ rigid body approach. Furthermore, force balance has to be achieved, pressures within the contact area $\Omega$ are nontensile, limited by an upper value and both contacting bodies are impenetrable. In order to calculate the displacement and thus the pressure distribution depending on the load, the gap between the contacting bodies and the material parameters, and an appropriate calculation domain, which includes the final contact area, have to be established. The initial gap between both contacting bodies can be derived from surface topographies measurements. The relationship between the surface displacement due to normal pressure and traction can be written as [31]:

$$
u_{z}\left(x, y, t_{i}\right)=\sum_{n=1}^{N_{\Omega}} D^{n}\left(x-x^{\prime}, y-y^{\prime}\right) p\left(x^{\prime}, y^{\prime}, t_{i}\right)+\sum_{n=1}^{N_{\Omega}} D^{s}\left(x-x^{\prime}, y-y^{\prime}\right) \mu\left(t_{i}\right)\left(x^{\prime}, y^{\prime}, t_{i}\right)
$$

The first part accounts for the deflection due to the pressure on top of the surface, the second accounts the deflection due to traction caused by friction. The set of in formulas (4)-(8) and formula (9) are solved using a single-loop iterative scheme based on the conjugate gradient method combined with a DC-FFT (Discrete-Convolution Fast Fourier Transform) technique to calculate the displacement $u_{z}[30,32,33]$. This method was applied to render the contact area and the contact pressure at the 100th, 80,000 th and 430,000 th and 500,000th cycle.

\section{Results}

\subsection{Material Loss}

The total material loss of pins and heads gained from weight loss measurements are comparatively shown in Figure 3 for both cleaning procedures. Clearly, there are marked differences as to the weight changes of the pins while the heads show a similar behavior. A simple linear regression for the heads shows that they have about the same average wear rate over the entire test period of $8 \mathrm{mg} / 100,000$ cycles $\left(R^{2}=0.99\right)$. 

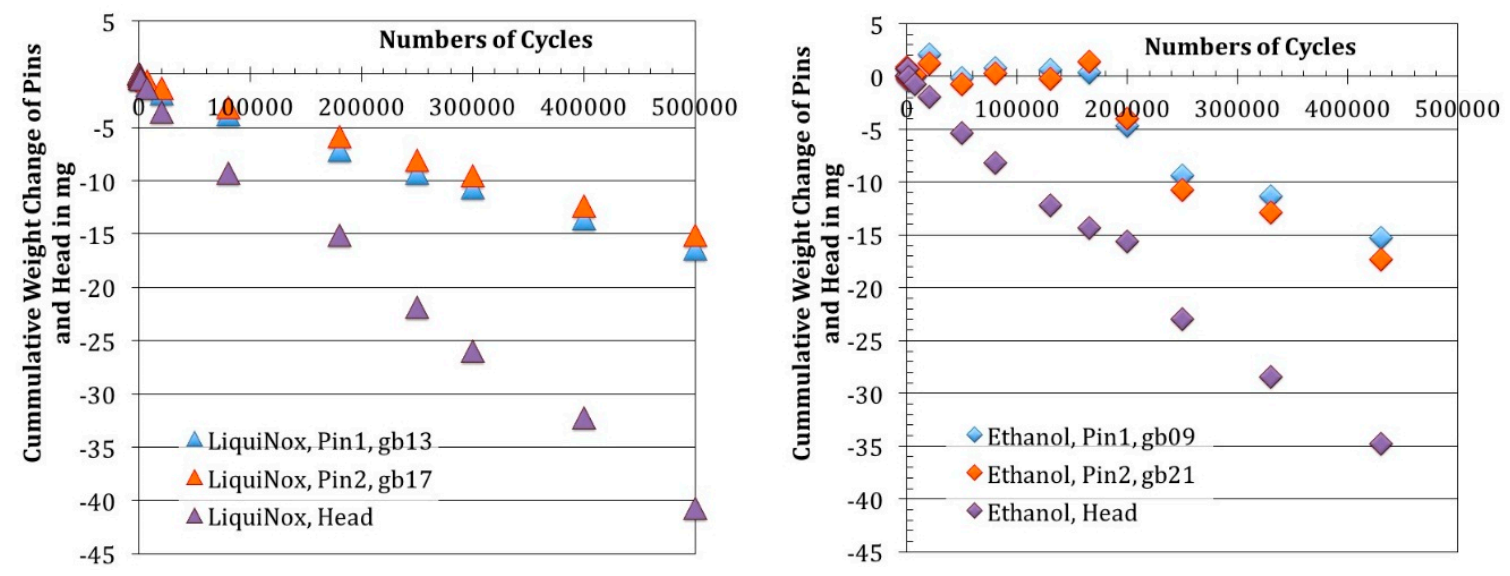

Figure 3. Weight Changes of Pins and Heads after different Cleaning Procedures. (a) Weight Changes after the Removal of any Organic Substance by Ethanol + LiquiNox Cleaning; (b) Weight Changes after Removal of any loose Debris by Ethanol Cleaning.

\subsubsection{Weight Changes after Removal of Organic Surface Residues (LiquiNox Cleaning)}

Despite the differences in their radial clearance the weight changes of both pins are essentially the same. A simple linear regression gives a rate of about $3 \mathrm{mg} / 100,000$ cycles for each pin $\left(R^{2}=0.99\right)$. Thus, both pins together wear less than the head. During run in (i.e., the first 7000 cycles; Figure 4) the steeper rates are visible. The run-in period was defined mechanism-wise on the basis of the SEM analyses for that range of cycles of the pins. For the head it is not possible to give a certain number of cycles, because the weight loss rate was stable already after less than 1000 cycles as were the wear appearances. Pin 2 with the higher incipient radial clearance shows a distinct wear loss during 500 cycles and later on less wear compared to Pin 1 . Such differences can be related to uncertainties, which are brought about by the fact that all samples had to be mounted and remounted for every analysis step. Thus, small differences may apply as to the exact positioning of the pins, which are unavoidable. Nevertheless, it can be seen that the run-in phase for pins and head comes to an end anywhere between 1500 and 7000 cycles.

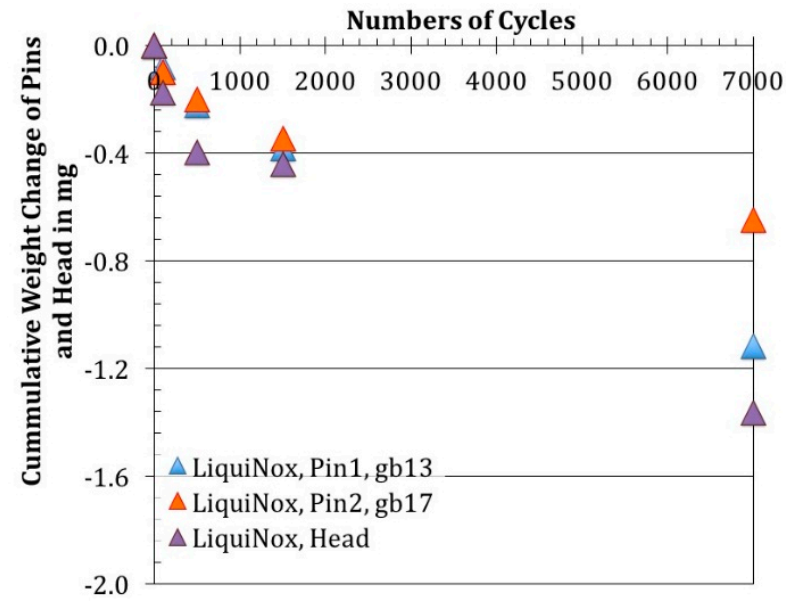

Figure 4. Weight Changes of Pins and Heads after the Removal of any Organic Substance by Ethanol + LiquiNox Cleaning.

Thus, the run-in is characterized by a high wear rate that levels off into a smaller one for steady state in agreement with most tribosystems [34,35]. 


\subsubsection{Weight Changes after Removal of Loose Debris (Ethanol Cleaning)}

If most of the tribomaterial is left intact on the surfaces by cleaning the samples in ethanol only, the rate of weight change of the pins and the head changes (Figure 3b). This already enlightens the importance of analyzing all bodies separately in order to understand the sliding wear behavior. Figure 5 shows that all bodies gain weight during the first 100 cycles, which would indicate negative wear. After another 400 cycles the head maintains its weight while the pins drop to about $-0.2 \mathrm{mg}$. At 1500 cycles the head shows its initial weight and wears further following the linear relationship mentioned above, while the pins maintain their weight at about 0 or $+1.8 \mathrm{mg}$ for another 170,000 cycles (Figure 3b).

The subsequent steady-state weight loss with about $7 \mathrm{mg} / 100,000$ cycles beyond 170,000 cycles is nearly as steep as it is for the head (Figure 3b). Still, after about 250,000 cycles, the wear of the head and the sum of wear losses of both pins remain slightly smaller than that of the head.

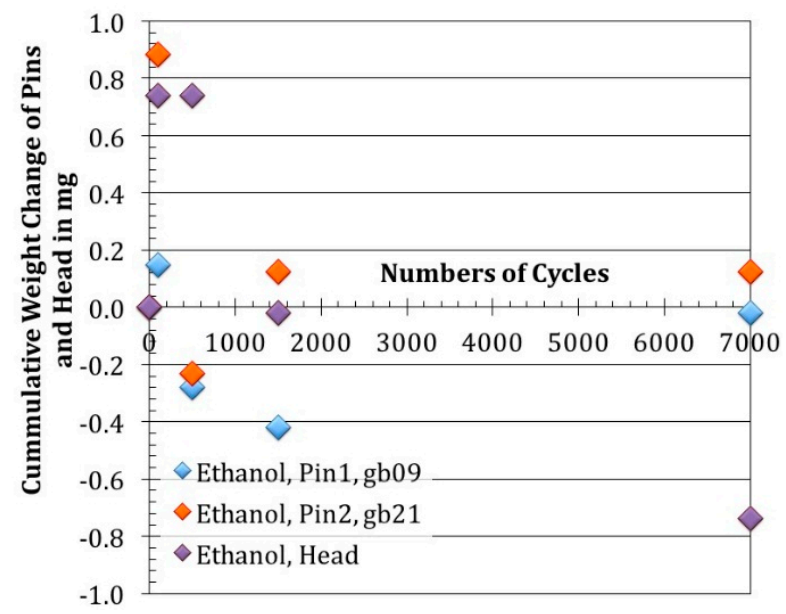

Figure 5. Weight Changes of Pins and Heads after the Removal of any Loose Debris by Ethanol Cleaning.

\subsection{Wear Appearances}

In order to understand the tribological behavior, the wear mechanisms have to be known. Thus, any difference of acting mechanisms should be visible by alterations of the wear appearances. Any organic layer of this type is accompanied by a distinct increase of the C-peak visible by EDS analyses [7-9,20,36]. Thus, the cleaning results of the LiquiNox treatment could be verified by EDS and were followed by the analyses of the wear appearances.

3.2.1. Wear Appearances after Ethanol- and after LiquiNox-Cleaning of Pin 1/Pin 2 vs. Head 1 (gb13/gb17 vs. 20258)

Figure 6 shows the wear appearances of Pin 2 at different test cycles also representing those of Pin 1 . After 100 cycles scratches prevail within the contact area together with some remains of a surface film appearing darker (Figure 6a). The multidirectional orientation of the grooves is attributed to the superposition of reversing rotational and translational movements of the pins and the head. Within the area confined to the scratches EDS revealed the chemical composition of the base material, while for the darker patches a C-content above $15 \mathrm{w} \%$ was determined. According to earlier findings it allows for the assumption that these patches represent the tribomaterial being typical for wear within proteinaceous media. Since the internal structure of this tribomaterial is not of interest for the present study, it has not been investigated further. The head reveals the same appearances (Figure 6b) while some of the scratches are filled with tribomaterial. In addition some wear particles are still attached to the surface. After 500 cycles the surface of the pin still shows some grooves but appears smoother 
in between (Figure 6c). The BSE-contrast is chosen for Figure $6 \mathrm{~d}$ in order to distinguish between the metal (higher density = light grey) and the organic tribomaterial (lower density = dark grey or black). It illustrates that the grooves are still prevailing while there is nearly no tribomaterial detectable.

At 1500 cycles Pin 2 is already completely covered by tribomaterial (Figure 6e). The head appears different (Figure 6f). The BSE-contrast shows the patchy distribution of tribomaterial, while nearly no grooves and scratches can be seen anymore. These appearances do not alter after 7000 cycles (Figure 6g). Pin 2 is covered by a somehow pitted tribomaterial, while that of the head remains patchy (Figure 6h). The pitted appearance stems from the topography of the underlying metal surfaces, as can be seen after removal of the tribomaterial by LiquiNox (Figure 7).

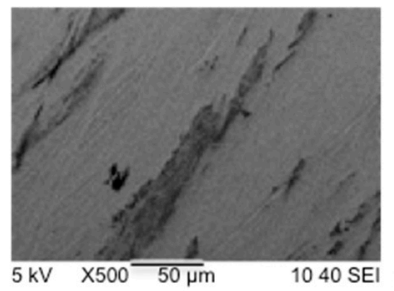

(a)

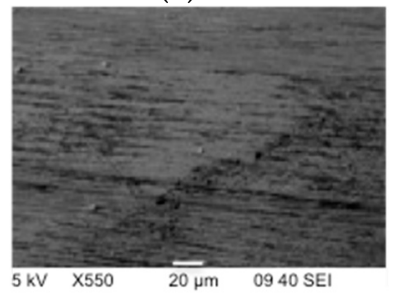

(b)

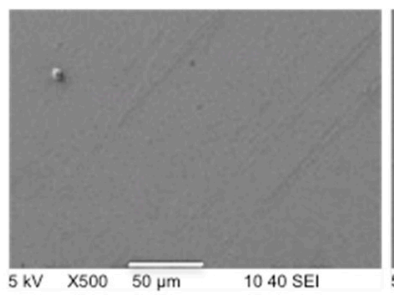

(c)

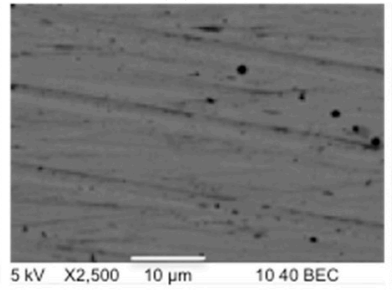

(d)

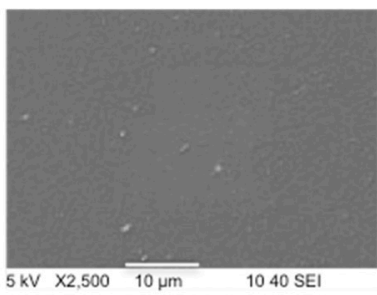

(e)

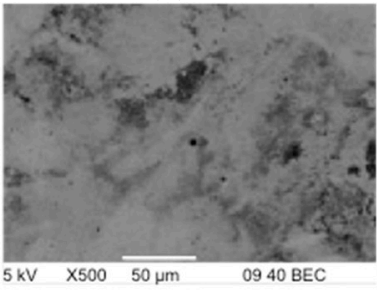

(f)

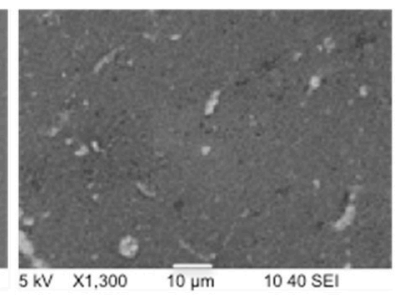

(g)

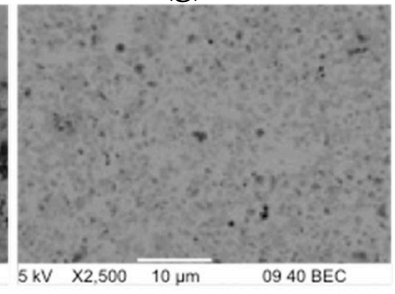

(h)

Figure 6. Wear Appearances during the First 7000 Cycles of Pin 2 and Head 1 after Ethanol-Cleaning. (a) Pin 2, 100 cycles, secondary-electron (SE); (b) Head 1, 100 cycles, SE; (c) Pin 2, 500 cycles, SE; (d) Head 1, 500 cycles, backscattered-electron (BSE)-contrast; (e) Pin 2, 1,500 cycles, SE; (f) Head 1, 1500 cycles, BSE-contrast; (g) Pin 2, 7,000 cycles, SE; (h) Head 1, 7000 cycles, BSE-contrast.

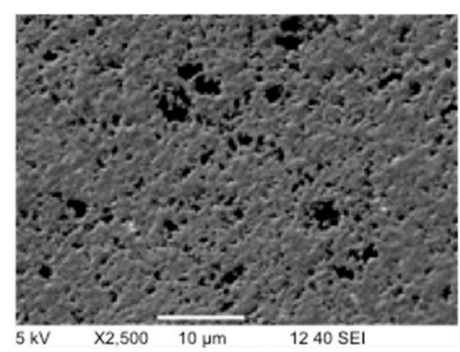

Figure 7. Pitted Metal Surfaces of Pin 2 and Head 1 after Cleaning in Ethanol and in LiquiNox. Pin 2, 7000 cycles, SE.

It also became clear from EDS-point analyses—not shown here-within the pits in Figure 7 that there are still remains of tribomaterial, which could not be completely removed by the chosen $10 \%$ LiquiNox solution. But in order to avoid any severe chemical alterations or corrosive attack to the base material the concentration of LiquiNox was not further increased. 
3.2.2. Wear Appearances after Ethanol-Cleaning of Pin 3/Pin 4 vs. Head 2 (gb09/gb21 vs. 20257)

Figure 8 shows the wear appearances of Pin 3 and Pin 4 at different test cycles. Obviously these are quite similar to those of the formerly shown tribocouples, even though the tribomaterial has not been removed after each test interval.

While the run-in is dominated by scratches and grooves for the first 100 cycles (Figure 8a) a tribomaterial is formed after 500 cycles (Figure 8b) and covers the entire surface at 1500 cycles (Figure 8c-f). Again the tribomaterial appears pitted for the pins and remains patchy for the head (Figure 8g,h).

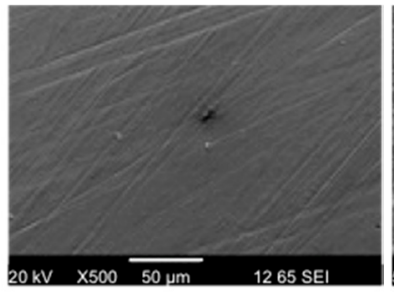

(a)

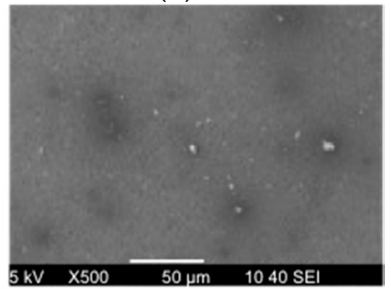

(e)

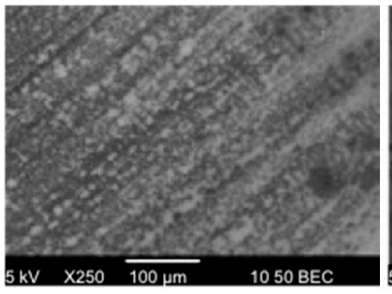

(b)

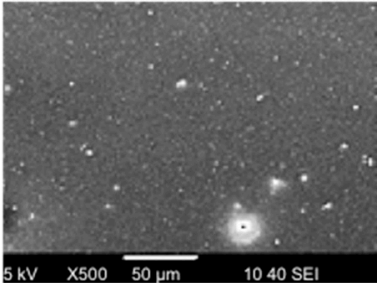

(f)

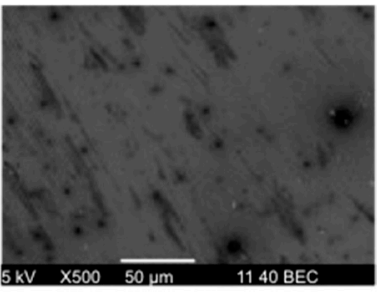

(c)

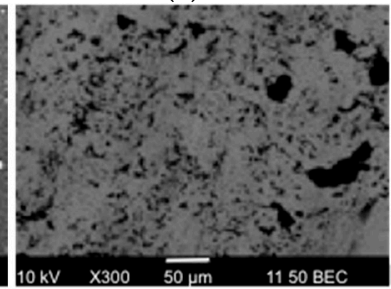

(g)

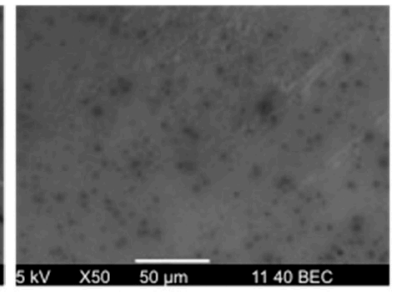

(d)

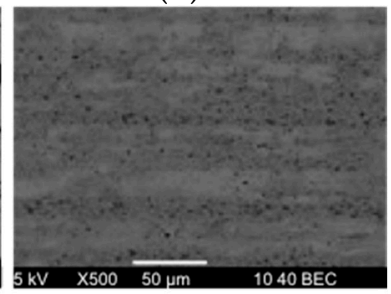

(h)

Figure 8. Wear Appearances of Pin 3, Pin 4, and Head 2 after Ethanol-Cleaning. (a) Pin 3, 100 cycles, SE; (b) Pin 3, 500 cycles, BSE; (c) Pin 3, 1,500 cycles, BSE; (d) Pin 3, 7000 cycles, BSE; (e) Pin 4, 200,000 cycles, SE; (f) Pin 4, 430,000 cycles, SE; (g) Head 2, 1,500 cycles, BSE-contrast; (h) Head 2, 200,000 cycles, BSE-contrast.

\subsection{Lubrication Regime}

It must be mentioned here that the values of Pin 3 comprise the tribomaterial sticking to the surface and result in a higher roughness compared to Pin 2 . The same is true for the increasing roughness values of the heads, which is rather brought about by the remains of the tribomaterial and only to a lesser extent by the roughening of the metal surfaces. Still these values indicate that the system was mainly operating within the boundary lubrication regime or the onset of mixed lubrication, corresponding well with the observed friction coefficient $(0.2-0.3)$. This indicates that elasto-hydrodynamic lubrication does not play any role and provokes the opportunity to analyze the contact conditions deeper, without the need to take hydrodynamic forces into account.

\section{Discussion}

The limited number of specimens would not support a quantitative approach to tribomaterial generation. Hence, it is the goal of this discussion to relate our qualitative findings to the existing literature and gain a more complete picture of the generation of tribomaterial. A second aspect of our discussion is the attempt to account for the introduction of half-space contact mechanics as a tool to better understand highly localized acting mechanisms in friction and wear under ultra-mild sliding wear conditions. 


\subsection{Wear Mechanisms and Tribological Behavior}

Both tribosystems, whether being ethanol or LiquiNox cleaned, show about the same wear loss and mostly a very similar sequence of wear appearances. In addition it should be mentioned that the coefficient of friction ranged from 0.2 to 0.3 for both systems and did not alter between run-in and steady state. Thus, both will be discussed together. The cumulated wear losses of both systems are neither dominated by the HC-CoCrMo heads nor by the LC-CoCrMo pins (Figure 9).

All bodies show abrasion during run-in. Due to the fact that no indications of any torn-off carbides from the head have been found, microcracking as a submechanism of abrasion [37] can be ruled out as in an earlier investigation [20]. Thus, microcutting and microploughing should prevail. Both are known to be quite efficient in removing material from surfaces and should lead to immediate wear loss. But this is not the case here. If the tribomaterial is not removed from the surfaces the specimens gain weight, which points towards tribochemical reactions. This wear mechanism is characterized by the generation of chemical reaction layers on the contact surfaces enclosing material from the bodies and the interfacial medium. Three sub-mechanisms are known today: the thermally driven and tribologically accelerated tribooxidation in gaseous media [38], tribocorrosion in liquid media [39] and mechanical mixing of solids [40]. Under the given conditions, the contact temperatures hardly exceed $60{ }^{\circ} \mathrm{C}$ [20] and any weight gain by oxide layers can be neglected, while the tribologically accelerated corrosive attack in proteinaceous medium would have brought about weight loss [41]. Thus, mechanical mixing should prevail. Thus, vortices have to be generated [42] that incorporate all materials in contact into a so-called tribomaterial consisting of CoCrMo and carbon from the BCS, which is supported by the EDS-analyses revealing more then $10 \mathrm{w} \% \mathrm{C}$ in such areas. Still, from classical research point of view it is thought that abrasion with $\mu \mathrm{m}$-deep grooves and tribochemical reactions are wear mechanisms that contradict each other [37]. This is not the case looking to the most recent findings in fine-machining with grooves smaller than $500 \mathrm{~nm}$, as well as in MD-simulations. Both would lead to a different conclusion. Here it is shown, that vortices necessary for mechanical mixing can be generated by severe plastic deformation of surface material leading to overfolding at microstructural obstacles, experimentally $[43,44]$ and theoretically $[45,46]$. According to molecular-dynamics (MD) simulations with pure $\mathrm{Cu}$ by such obstacles could be grain boundaries. Combining this with the abrasion-model of [37] the run-in within this tribosystem would then be dominated by microploughing, rather than micocutting. Thus, the obvious scratches and grooves are likely being brought about by severe plastic deformation of surfaces but without any distinct wear loss, as indicated in [37,47]. By the increasing numbers of cycles the interfacial medium is further mixed into such severely deformed near-surface material, which is accompanied by a grain refinement down to the nanoscale [48-52]. This hypothesis is further supported by the observed coefficient of friction, which promotes near-surface plastic deformation over sub-surface plasticity. Thus, the more such plastic deformation takes place the more effective should be the formation of tribomaterial. Figure 10 shows the weight of the tribomaterial, which has been removed by the LiquiNox cleaning. Obviously most of the tribomaterial is generated within the run-in period but due to the high local contact pressures it is immediately squeezed out of the contact. After the surfaces became adjusted by plastic deformation (or wear) at about 7000 cycles and the local contact pressure decreases, the tribomaterial stays inside the contact area and the effect of abrasion weakens. Now the amount of tribomaterial generated is about the same for the remaining 500,000 cycles. The rates of generation and removal differ for any single contact and cannot be generalized. According to the weight changes (Figure 5) Pin 2 generated more tribomaterial in 100 cycles than Pin 1 . After 500 cycles both showed the same weight loss, while Pin 2 even gained weight again at 1500 cycles. Now Pin 1 still shows its initial weight after 7000 cycles. Thus, the steady disturbance of the contact situation by dismounting and remounting may influence the individual numbers. Nevertheless the main finding is that the generation of a sufficient amount of tribomaterial can alter the total weight change of the pins. 


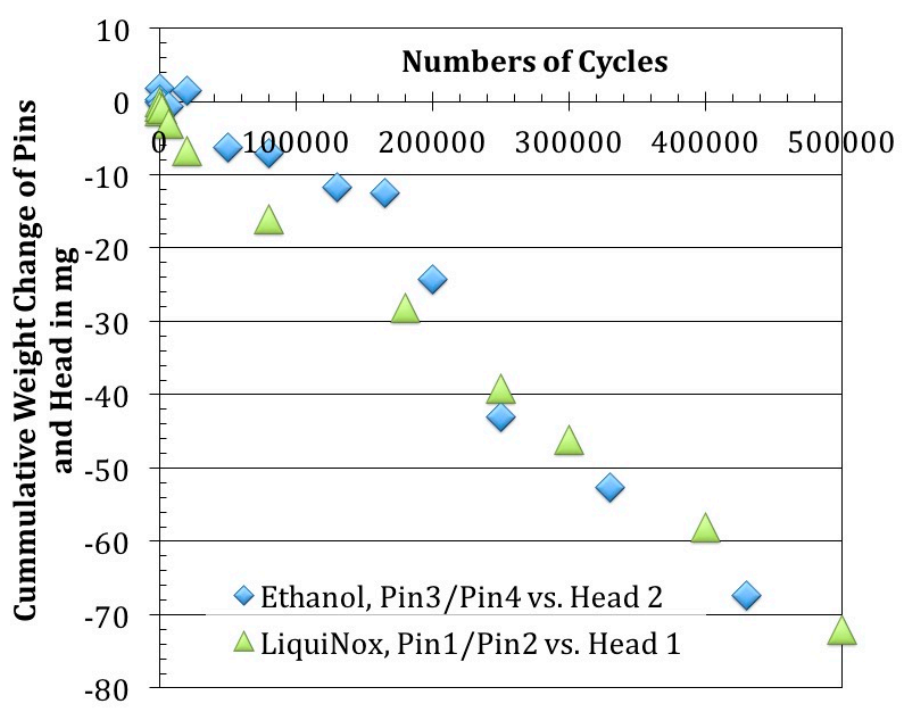

Figure 9. Accumulated Weight Changes of Both Tribosystems.

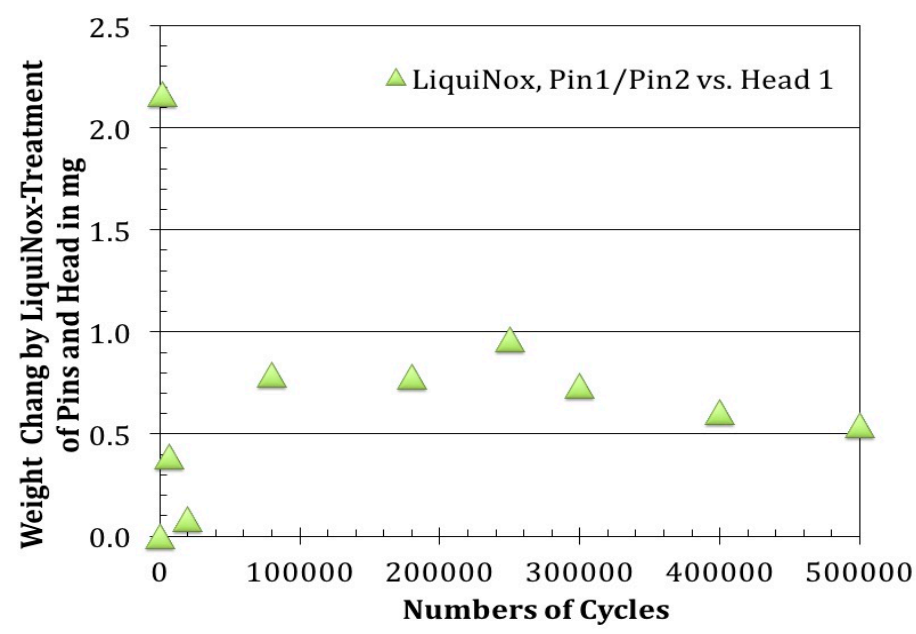

Figure 10. Weight Difference of Pins and Head before and after LiquiNox Cleaning. This represents the Weight of the Organic Tribomaterial.

Now the development of the contact characteristics steadily leads to a steady decrease of the contact pressure and, therefore, the rate of generation of tribomaterial. If one divides the weight of the tribomaterial given in Figure 10 by the numbers of cycles in between the intervals the generation rate of tribomaterial decreases more than one order of magnitude, starting from $1.4 \mu \mathrm{g} /$ cycle down to $0.075 \mu \mathrm{g} /$ cycle.

In steady state the acting wear mechanisms after about 7000 cycles are tribochemical reactions (by further mechanical mixing but at a decreasing rate) and surface fatigue indicated by the resulting micro-pitting. The latter might be brought about by rolling wear particles causing indentations, cracks parallel to the surface causing delaminations, or both. In addition, a corrosive attack of the edges of the pits cannot be fully ruled out. Still, the wear rates of pins and heads stay nearly constant and follow linearly with the numbers of cycles. Due to the fact that the generation of tribomaterial is exponentially decreasing (with varying exponents for run-in and steady state), it does not slow down or even balance further weight loss for the ethanol-cleaned couples. If the tribomaterial is removed by LiquiNox there is no weight loss compensation at all. Obviously, the smoother contact conditions under steady state characterized by surface fatigue do not allow for a fast enough generation of 
mechanically mixed tribomaterial like in run-in where microploughing prevails. The question certainly arises why the tribomaterial is more pronounced for the concave pins compared to the convex heads' surfaces. One answer could rise from the fact that the pins surfaces are always in contact and, therefore, are stressed more constantly by microploughing on the sub- $\mu \mathrm{m}$ scale. As a consequence this could lead to a more distinct generation of tribomaterial. This might also explain the slightly smaller weight changes of the pins compared with the balls in this study.

However, this hypotheses cannot be validated at this point and has to be left open for future research. Still it becomes clear that as soon as the tribomaterial covers the pins' surfaces and governs the contact situation the run-in phase is finished. Now an even more interesting question according to the authors' opinion appears; how big is the critical local contact pressure that allows for microploughing and the generation of a sufficient amount of tribomaterial but does not immediately remove it from the contact area? In other words where is the balance that minimizes material loss? From the nominal or Hertzian contact stresses one cannot answer such question. Thus, in order to understand the local contact conditions better, contact mechanics simulation base on the actual topography might give a deeper insight.

\subsection{Contact Conditions and Tribological Behavior}

The numbers shown in Table 3 appear to contradict the idea that LiquiNox removes the tribomaterial. However Pin 1, Pin 2, and Head 2 are only cleaned from any loose debris and the topography is, therefore, characterized by the pitted and scarred tribomaterial that leads to a rougher topography. Thus, one looks directly at the essential part of the lubricant that may have separated both bodies in contact after run-in. Newer findings also suggest that any classical model underestimates the film thickness of proteinaceous liquids for their gel-type lubrication effect [28]. Thus, it also must be left open whether the smoother topography measured after LiquiNox-cleaning is a valid input for calculations using formulas 1 and 2 .

Table 3. Examples of $\lambda$-values according to formulas (1) and (2) and the accounting for ranges of the entraining velocity and the viscosity as described above.

\begin{tabular}{cccc}
\hline Cycles & $\boldsymbol{R}_{\mathbf{a}}$ Pin $\mathbf{3}$ in $\boldsymbol{\mu m}$ & $\boldsymbol{R}_{\mathbf{a}}$ Head $\mathbf{~ i n ~} \boldsymbol{\mu m}$ & $\lambda$ \\
\hline 100 & 0.021 & 0.092 & $0.0003-0.07$ \\
50,000 & 0.034 & 0.114 & $0.0004-0.09$ \\
430,000 & 0.093 & 0.248 & $0.0003-0.1$ \\
\hline & $R_{\mathrm{a}}$ Pin 2 in $\mu \mathrm{m}$ & $R_{\mathrm{a}}$ Head 1 in $\mu \mathrm{m}$ & $\lambda$ \\
80,000 & 0.011 & 0.059 & $0.0004-0.07$ \\
500,000 & 0.004 & 0.054 & $0.0002-0.03$ \\
& 0.008 & 0.083 & $<0.003$ \\
\hline
\end{tabular}

Nevertheless on the basis of the computed $\lambda$-value we assume that boundary lubrication prevails. During the first 100 cycles all surfaces investigated showed no tribomaterial but scratches and grooves brought about by high localized contact pressures. Figure 11 shows the results of the contact pressure distribution after 100 cycles derived by the half-space model shown in formula (9). Here the elastic-plastic cutoff pressure value has been chosen to be $1500 \mathrm{MPa}$ as will be explained further.

In both cases it becomes clear that high pressures only act locally. If one counts the area that would apply for a plastic flow at $1500 \mathrm{MPa}$ it would only be about $2 \%$ to $3 \%$ of the affected contact area $(\mathrm{p}(\mathrm{x}, \mathrm{y}, \mathrm{t})>0 \mathrm{MPa})$. The reader should keep in mind that the term "affected area" describes the fraction of the nominal contact area at which the local contact pressure is bigger than zero. Since abrasion and its submechanisms bring about a mainly monotonic stress-strain loading the cutoff pressure for plastic flow was chosen on the basis of monotonically measured properties, e.g., from hardness-in a first and rough approximation-following the cavity model of [53] and the relations found by [54] for solution annealed solid CoCrMo-alloy samples. Thus, it would be about $1 / 3$ of the hardness of 
the metal matrix, which would be $1500 \mathrm{MPa}$. Such high contact pressures would then bring about a high wear rate during the first 100 cycles as illustrated in Figure 3 (-13 ng/cycle for Pin 1/Pin 2 vs. Head 1) and at the same time generate tribomaterial by severe plastic deformation ( $+17 \mathrm{ng} / \mathrm{cycle}$ for Pin 3/Pin 4 vs. Head 2) as well as overfolding according to [46] as can also be seen from Figures 6 and 11.

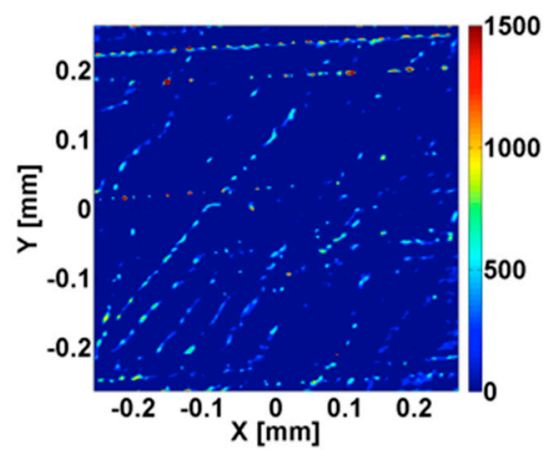

(a)

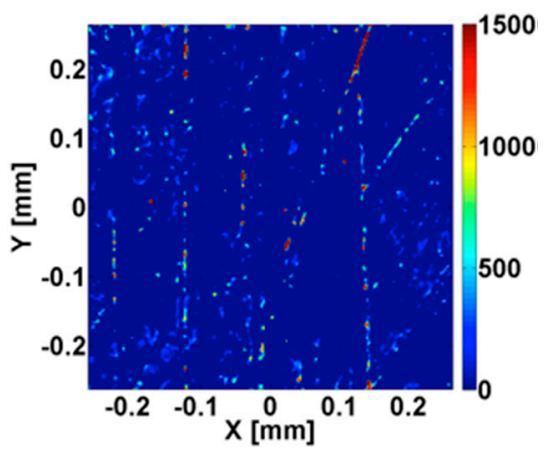

(b)

Figure 11. Contact Pressure Distribution after 100 cycles at an Elastic-Ideal Plastic-Cutoff Pressure Value of $1500 \mathrm{MPa}$. The vertical color bars represent the local contact pressure in MPa. (a) Liquinox-Cleaning, Pin 2 vs. Head 1; (b) Ethanol-Cleaning, Pin 3 vs. Head 2.

Under steady state the problem arises that surface fatigue prevails and that for any computer simulation one would now need a cyclic cutoff pressure, which cannot be quantified today. Thus—and again in a first and rough approximation — the shake-down model as described in [53] could be applied as shown in [55] leading to a cutoff pressure of $750 \mathrm{MPa}$, which is roughly 1.1 times the fatigue limit of such metal. The influence of the tribomaterial is neglected here because it has unknown properties. In addition, since the thickness would be only 1/10 of the lateral grid dimension it can be neglected completely [56]. In addition, the unknown properties of the gel-type lubrication under monotonic and cyclic loading require more research in the future as to its load bearing effect under boundary and mixed lubrication. Nevertheless under steady state our cyclic cutoff pressure would bring about the distributions shown in Figure 12 for the topography after LiquiNox-cleaning. It is important to notice that because of the lack of any precise measurement of such cyclic cutoff pressure, these pictures can only show a qualitative number for the pressure but still provide a quite accurate description of the affected area $(\mathrm{p}(\mathrm{x}, \mathrm{y}, \mathrm{t})>0 \mathrm{MPa})$.

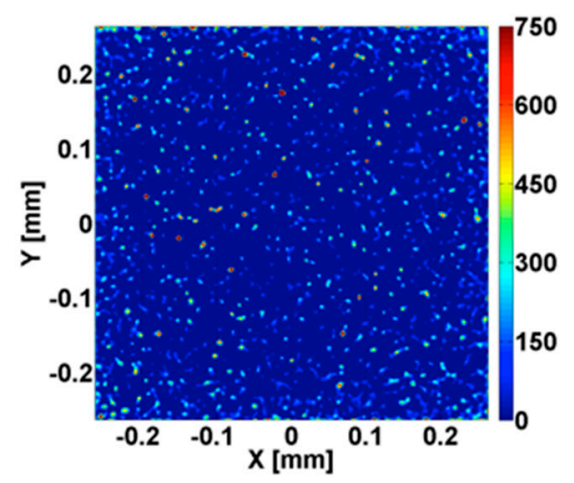

(a)

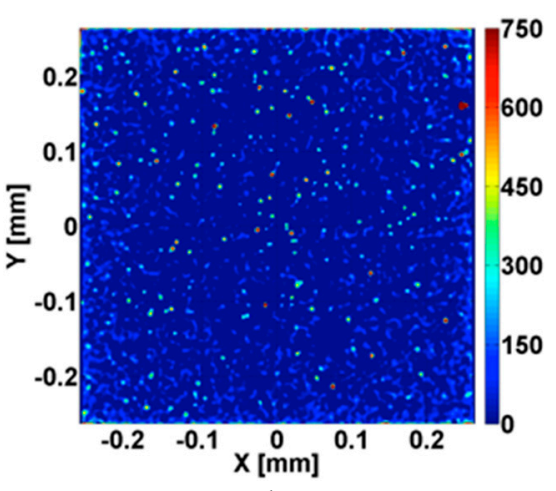

(b)

Figure 12. Contact Pressure Distribution at a Elastic-ideal Plastic-Cutoff Pressure Value of $750 \mathrm{MPa}$ of Pin 2 vs. Head1 after LiquiNox-Cleaning. The vertical color bars represent the local contact pressure in MPa. (a) after 80,000 cycles; (b) after 500,000 cycles. 
Again only very few areas are subjected to "cyclic" plastic flow but the gross load is more evenly distributed compared to run-in. Even if under such conditions wear particles are rotating leading to multiple indentations (as a submechanism of surface fatigue driven by cyclic plastic strains) the effectiveness to remove matter from a surface decreases at least by an order of magnitude relative to 2-body abrasion as has been shown by $[57,58]$. If delamination (as a submechanism of surface fatigue driven by cyclic elastic strains) would prevail the loss of matter is even less [37]. Thus, the wear rate is smaller during steady-state by changing from abrasion to surface fatigue both in combination with tribochemical reactions. But this would also lead to a less pronounced severe plastic deformation and, therefore, to a lesser generation of tribomaterial [59]. For the chosen laboratory tribosystem, the generation rate of tribomaterial decreases exponentially over the number of cycles while the wear rates stay constant under steady state at about $0.14 \mathrm{ng} /$ cycle for Pin 1/Pin 2 vs. Head 1 above 80,000 cycles.

Due to the fact that the metallo-organic tribomaterial will be softer than the metal it would deform and, therefore, hinder or prevent yielding of the metal itself. Thus, the wear particles would originate from the tribomaterial and the properties of this layer will dominate the wear process instead of those of the underlying metal. Still, any particle within the tribomaterial must have been generated at the interface between the solid metal, which is nanocrystalline at this position, and the tribomaterial. Due to the still unknown criteria and mechanisms for the detachment of a nanoparticle from such structure we only can assume today, that the tribomaterial is squeezed aside at the points of a certain contact pressure. This would result in a solid-solid contact of the asperities followed by the tearing-off of a nanosize wear particle.

\section{Limitations}

There was only one pin per radial clearance available because three equal radial clearances could not be manufactured by the university's workshop; thus, here, neither quantitative values nor any statistics but only tendencies are given. Still the wear rates of the heads are quite close, which gives a 1st and rough hint on the validity of the measured values relative to each other. The $\lambda$-values are derived by classical theory, which may not accurately describe the system. It has been shown by $[27,28,60,61]$ that with proteins a gel-type lubrication is more likely. Thus, the calculated $\lambda$-values may interpret the contact situation incorrectly, which could be more within the mixed regime. Still we do not know the exact properties of the lubricant used and, therefore, used the worst-case scenario, because it has no influence on the main outcome.

\section{Conclusions}

This analysis revealed that even though material is worn from the 1st cycle during run-in, the specimens gained weight by generating and accumulating tribomaterial. Afterwards, the loss of material surpasses the generation of new tribomaterial and a steady weight-loss is measured. Apparently, the incipient high local surface stresses, characterized by scratches and grooves through microploughing, accelerate the tribochemical reactions. After completion of run-in, the contact situation reverses being mostly characterized by surface fatigue in combination with a much smaller generation rate of tribomaterial. Thus, the weight gain is smaller than the weight loss and wear proceeds.

Future work will concentrate on the properties of tribomaterial in contact. In addition, the quantification of the critical local pressure values should be investigated that on the one hand allow for a sufficiently high generation rate of tribomaterial and on the other hand keep it in contact instead of wearing it off or squeezing it out.

Acknowledgments: Parts of this study has been supported by the NIH under grant RC2AR058993 and was carried out at the Rush University Medical Center, Department of Orthopedic Surgery, Chicago, IL, USA. Thus the authors would like to thank Joshua J. Jacobs, Michel Laurent, Robert Urban, Deborah Hall, and Carol Pacione for the support during wear tests and surface analyses.

Author Contributions: Alfons Fischer and Markus Wimmer conceived and designed the experiments; Christian Schoß performed the experiments; Daniel Stickel and Rob Bosman analyzed all measured geometrical, 
kinematic, and topographical data and carried out all half-space calculations; Markus Wimmer contributed reagents/materials/analysis tools and reviewed the paper; Alfons Fischer wrote the paper.

Conflicts of Interest: The authors declare no conflict of interest.

\section{References}

1. Kurtz, S.M.; Ong, K.L.; Lau, E.; Greenwald, A.S.; Bozic, K.J. Prevalence of Metal-on-Metal Bearings in the United States. In Metal-on-metal Total Hip Replacement Devices—stp1560; Kurtz, S.M., Greenwald, A.S., Mihalko, W.M., Lemons, J.E., Eds.; ASTM International: Wear Conshohocken, PA, USA, 2013; pp. 3-18.

2. Bozic, K.J.; Kurtz, S.; Lau, E.; Ong, K.; Chiu, V.; Vail, T.P.; Rubash, H.E.; Berry, D.J. The epidemiology of bearing surface usage in total hip arthroplasty in the united states. J. Bone Joint Surg. Am. 2009, 91, 1614-1620. [CrossRef] [PubMed]

3. Morlock, M.M.; Bishop, N.; Zustin, J.; Hahn, M.; Ruther, W.; Amling, M. Modes of implant failure after hip resurfacing: Morphological and wear analysis of 267 retrieval specimens. J. Bone Joint Surg. Am. 2008, 90, 89-95. [CrossRef] [PubMed]

4. De Haan, R.; Pattyn, C.; Gill, H.S.; Murray, D.W.; Campbell, P.A.; De Smet, K. Correlation between inclination of the acetabular component and metal ion levels in metal-on-metal hip resurfacing replacement. J. Bone Joint Surg.Ser. B 2008, 90, 1291-1297. [CrossRef] [PubMed]

5. Hart, A.J.; Muirhead-Allwood, S.; Porter, M.; Matthies, A.; Ilo, K.; Maggiore, P.; Underwood, R.; Cann, P.; Cobb, J.; Skinner, J.A. Which factors determine the wear rate of large-diameter metal-on-metal hip replacements? Multivariate analysis of two hundred and seventy-six components. J. Bone Joint Surg. Am. Vol. 2013, 95, 678-685. [CrossRef] [PubMed]

6. Hannemann, F.; Hartmann, A.; Schmitt, J.; Lützner, J.; Seidler, A.; Campbell, P.; Delaunay, C.P.; Drexler, H.; Ettema, H.B.; García-Cimbrelo, E.; et al. European multidisciplinary consensus statement on the use and monitoring of metal-on-metal bearings for total hip replacement and hip resurfacing. Orthop. Traumatol. Surg. Res. 2013, 99, 263-271. [CrossRef] [PubMed]

7. Wimmer, M.A.; Sprecher, C.; Hauert, R.; Täger, G.; Fischer, A. Tribochemical reaction on metal-on-metal hip joint bearings-A comparison between in vitro and in vivo results. Wear 2003, 255, 1007-1014. [CrossRef]

8. Wimmer, M.A.; Mathew, M.T.; Laurent, M.P.; Nagelli, C.; Liao, Y.; Marks, L.D.; Pourzal, R.; Fischer, A.; Jacobs, J.J. Tribochemical Reactions in Metal-on-metal Hip Joints Influence Wear and Corrosion. In ASTM STP 1560 Symposium on Metal-on-Metal Total Hip Replacement Devices; Kurtz, S., Greenwald, A.S., Mihalko, W.M., Clemson, J.E., Eds.; ASTM: West Conshohocken. PA, USA, 2013; Volume 1560 STP, pp. 292-309.

9. Liao, Y.; Pourzal, R.; Wimmer, M.A.; Jacobs, J.J.; Fischer, A.; Marks, L.D. Graphitic tribological layers in metal-on-metal hip replacements. Science 2011, 334, 1687-1690. [CrossRef] [PubMed]

10. Hesketh, J.; Ward, M.; Dowson, D.; Neville, A. The composition of tribofilms produced on metal-on-metal hip bearings. Biomaterials 2013, 35, 2113-2119. [CrossRef] [PubMed]

11. Pourzal, R.; Martin, E.J.; Vajpayee, S.; Liao, Y.; Wimmer, M.A.; Shull, K.R. Investigation of the role of tribofilms in self-mating cocrmo systems utilizing a quartz crystal microtribometer. Tribol. Int. 2014, 72, 161-171. [CrossRef]

12. Zeng, P.; Sharp, J.; Rana, A.; Thompson, R.; Rainforth, W.M.; Cook, R.B. Sub-surface characterisation of tribological contact zone of metal hip prostheses. J. Phys. Conf. Ser. 2015, 644. [CrossRef]

13. Büscher, R.; Täger, G.; Dudzinski, W.; Gleising, B.; Wimmer, M.A.; Fischer, A. Subsurface microstructure of metal-on-metal hip joints and its relationship to wear particle generation. J. Biomed. Mater. Res. B Appl. Biomater. 2005, 72, 206-214. [CrossRef] [PubMed]

14. Pourzal, R.; Catelas, I.; Theissmann, R.; Kaddick, C.; Fischer, A. Characterization of wear particles generated from cocrmo alloy under sliding wear conditions. Wear 2011, 271, 1658-1666. [CrossRef] [PubMed]

15. Pourzal, R. Possible Pathways of Particle Formation in Cocrmo Sliding Wear. Ph.D. Thesis, University Duisburg-Essen, Duisburg, Germany, 2011.

16. Godet, M. The third-body approach: A mechanical view of wear. Wear 1984, 100, 437-452. [CrossRef]

17. Rigney, D.A. Transfer, mixing and associated chemical and mechanical processes during the sliding of ductile materials. Wear 2000, 245, 1-9. [CrossRef]

18. Rigney, D.A.; Karthikeyan, S. The evolution of tribomaterial during sliding: A brief introduction. Tribol. Lett. 2010, 39, 3-7. [CrossRef] 
19. Wimmer, M.A.; Nassutt, R.; Lampe, F.; Schneider, E.; Morlock, M.M. A New Screening Method Designed for Wear Analysis of Bearing Surfaces Used in Total Hip Arthroplasty. In ASTM STP 1346 Alternative Bearing Surfaces in Total Joint Replacement; Jacobs, J.J., Craig, T.L., Eds.; ASTM: West Conshohocken, PA, USA, 1998; Volume 1346, pp. 30-43.

20. Wimmer, M.A.; Loos, J.; Heitkemper, M.; Fischer, A. The acting wear mechanisms on metal-on-metal hip joint bearings-in vitro results. Wear 2001, 250, 129-139. [CrossRef]

21. Dowson, D.; Jin, Z.M. Metal-on-metal hip joint tribology. Proc. Inst. Mech. Eng. H J. Eng. Med. 2006, 220, 107-118. [CrossRef]

22. Tallian, T.E. On competing failure modes in rolling contact. ASLE Trans. 1967, 10, 418-439. [CrossRef]

23. Seller, P.C.; Dowson, D.; Wright, V. The rheology of synovial fluid. Rheol. Acta 1971, 10, 2-7. [CrossRef]

24. Mazzucco, D.; McKinley, G.; Scott, R.D.; Spector, M. Rheology of joint fluid in total knee arthroplasty patients. J. Orthop. Res. Off. Publ. Orthop. Res. Soc. 2002, 20, 1157-1163. [CrossRef]

25. Yao, J.; Laurent, M.; Johnson, T.; Blanchard, C.; Crowninshield, R. The influences of lubricant and material on polymer/CoCr sliding friction. Wear 2003, 255, 780-784. [CrossRef]

26. Fan, J.; Myant, C.W.; Underwood, R.; Cann, P.M.; Hart, A. Inlet protein aggregation: A new mechanism for lubricating film formation with model synovial fluids. Proc. Inst. Mech. Eng. H J. Eng. Med. 2011, 225, 696-709. [CrossRef]

27. Myant, C.; Underwood, R.; Fan, J.; Cann, P.M. Lubrication of metal-on-metal hip joints: The effect of protein content and load on film formation and wear. J. Mech. Behav. Biomed. Mater. 2012, 6, 30-40. [CrossRef] [PubMed]

28. Myant, C.; Cann, P. In contact observation of model synovial fluid lubricating mechanisms. Tribol. Int. 2013, 63, 97-104. [CrossRef]

29. Vrbka, M.; Nečas, D.; Hartl, M.; Křupka, I.; Urban, F.; Gallo, J. Visualization of lubricating films between artificial head and cup with respect to real geometry. Biotribology 2015, 1-2, 61-65. [CrossRef]

30. Ungureanu, I.; Spinu, S. A simplified model for pressure distribution in elastic-Perfectly plastic contact. Ann. Oradea Univ. 2010, XIX, 1-8.

31. Willner, K. Fully coupled frictional contact using elastic halfspace theory. ASME J. Tribol. 2008, 130, 1-8. [CrossRef]

32. Polonsky, I.A.; Keer, L.M. A numerical method for solving rough contact problems based on the multi-level multi-summation and conjugate gradient techniques. Wear 1999, 231, 206-219. [CrossRef]

33. Liu, S.; Wang, Q.; Liu, G. A versatile method of discrete convolution and FFT (DC-FFT) for contact analyses. Wear 2000, 243, 101-111. [CrossRef]

34. Chang, L. Determination of the sampling interval in surface roughness measurements with implications to engineering tribo-surface characterization and evaluation. Proc. Inst. Mech. Eng. J. J. Eng. Tribol. 2009, 223, 675-681. [CrossRef]

35. Stickel, D.; Fischer, A. The alteration of micro-contact parameters during run-in and their effect on the specific dissipated friction power. Tribol. Int. 2015, 82, 287-296. [CrossRef]

36. Milocev, I.; Remckar, M. In vivo production of nanosized metal wear debris formed by tribochemical reaction as confirmed by high-resolution tem and xps analyses. J. Biomed. Mater. Res. A 2009, 91, 1100-1110. [CrossRef] [PubMed]

37. Zum Gahr, K.H. Microstructure and Wear of Materials; Elsevier Science Publishers: Amsterdam, The Netherlands, 1987; Volume 10.

38. Quinn, T.F.J. Review of oxidational wear. Part I: The origins of oxidational wear. Tribol. Int. 1983, 16, $257-271$. [CrossRef]

39. Landolt, D.; Mischler, S.; Stemp, M. Electrochemical methods in tribocorrosion: A critical appraisal. Electrochim. Acta 2001, 46, 3913-3929. [CrossRef]

40. Rigney, D.A.; Hammerberg, J.E. Mechanical Mixing and the Development of Nanocrystalline Material During the Sliding of Metals. In Advanced Materials in the 21st Century: The 1999 Julia R. Weertman Symposium; Chung, Y.W., Dunand, D.C., Liaw, P., Olson, G.B., Eds.; The Minerals, Metals \& Materials Society: Warrendale, PA, USA, 1999; pp. 465-474.

41. Mischler, S.; Debaud, S.; Landolt, D. Wear-accelerated corrosion of passive metals in tribocorrosion systems. J. Electrochem. Soc. 1998, 145, 750-758. [CrossRef] 
42. Karthikeyan, S.; Wu, J.H.; Rigney, D.A. The Role of Vorticity in the Formation of Tribomaterial During Sliding. In MRS Fall Meeting, Symposium on Nanoscale Materials and Modeling-Relations Among Processing, Microstructure, and Mechanical Properties; Anderson, P.M., Foecke, T., Misra, A., Rudd, R.E., Eds.; MRS: Warrendale, PA, USA; Boston, MA, USA, 2004; Volume 821, pp. 9.6.1-9.6.6.

43. Sundaram, N.K.; Guo, Y.; Chandrasekar, S. Mesoscale folding, instability, and disruption of laminar flow in metal surfaces. Phys. Rev. Lett. 2012, 109, 106001. [CrossRef] [PubMed]

44. Guo, Y.; Sundaram, N.; Mahato, A.; Compton, D.W.; Chandrasekar, S. Folding and transitions in plastic deformation in metal sliding and machining. In Proceedings of the 41st North American Manufacturing Research Conference 2013, NAMRC 2013, Madison, WI, USA, 10-14 June 2013; pp. 458-462.

45. de Beer, S.; Müser, M.H. Viewpoint-Surface folds make tears and chips. Physics 2012, 5, 106001. [CrossRef]

46. Beckmann, N.; Romero, P.A.; Linsler, D.; Dienwiebel, M.; Stolz, U.; Moseler, M.; Gumbsch, P. Origins of folding instabilities on polycrystalline metal surfaces. Phys. Rev. Appl. 2014, 2, 064004. [CrossRef]

47. Hokkirigawa, K.; Kato, K. An experimental and theoretical investigation of ploughing, cutting and wedge formation during abrasive wear. Tribol. Int. 1988, 21, 51-57. [CrossRef]

48. Rigney, D.A.; Glaeser, W.A. The significance of near surface microstructure in the wear process. Wear 1978, 46, 241-250. [CrossRef]

49. Rigney, D.A. Microstructural evolution during sliding. Procs. ASM Sympos. Wear Eng. Mater. 1998, 3-12.

50. Büscher, R.; Fischer, A. The pathways of dynamic recrystallization in all-metal hip joints. Wear 2005, 887-897. [CrossRef]

51. Pourzal, R.; Theissmann, R.; Williams, S.; Gleising, B.; Fisher, J.; Fischer, A. Subsurface changes of a mom hip implant below different contact zones. J. Mech. Behav. Biomed. Mater. 2009, 2, 186-191. [CrossRef] [PubMed]

52. Fischer, A.; Weiss, S.; Wimmer, M.A. The tribological difference between biomedical steels and cocrmo-alloys. J. Mech. Behav. Biomed. Mater. 2012, 1, 50-62. [CrossRef] [PubMed]

53. Johnson, K.L. Contact Mechanics; Cambridge University Press: Cambridge, UK, 1985.

54. Gaytan, S.M.; Murr, L.E.; Martinez, E.; Martinez, J.L.; MacHado, B.I.; Ramirez, D.A.; Medina, F.; Collins, S.; Wicker, R.B. Comparison of microstructures and mechanical properties for solid and mesh cobalt-base alloy prototypes fabricated by electron beam melting. Metall. Mater. Trans. A Phys. Metall. Mater. Sci. 2010, 41, 3216-3227. [CrossRef]

55. Prasad, S.V.; Michael, J.R.; Majumdar, B.S.; Battaile, C.C.; Moody, N.R.; Cordill, M.J.; Jungk, J.M.; Bammann, D.J. Modeling of Friction-Induced Deformation and Microstructures; Sandia National Laboratories: Albuquerque, NM, USA; Livermore, CA, USA, 2006.

56. Bosman, R.; Schipper, D.J. Mild wear maps for boundary lubricated contacts. Wear 2012, 280-281, 54-62. [CrossRef]

57. Misra, A.; Finnie, I. Correlations between two-body and three-body abrasion and erosion of metals. Wear 1981, 68, 33-39. [CrossRef]

58. Fischer, A. Well-founded selection of materials for improved wear resistance. Wear 1996, 194, $238-245$. [CrossRef]

59. Wimmer, M.A.; Laurent, M.P.; Mathew, M.T.; Nagelli, C.; Liao, Y.; Marks, L.D.; Jacobs, J.J.; Fischer, A. The effect of contact load on cocrmo wear and the formation and retention of tribofilms. Wear 2015, 332-333, 643-649. [CrossRef] [PubMed]

60. Myant, C.; Cann, P. On the matter of synovial fluid lubrication: Implications for metal-on-metal hip tribology. J. Mech. Behav. Biomed. Mater. 2014, 34, 338-348. [CrossRef] [PubMed]

61. Parkes, M.; Myant, C.; Cann, P.M.; Wong, J.S.S. Synovial fluid lubrication: The effect of protein interactions on adsorbed and lubricating films. Biotribology 2015, 1-2, 51-60. [CrossRef]

(C) 2016 by the authors; licensee MDPI, Basel, Switzerland. This article is an open access article distributed under the terms and conditions of the Creative Commons Attribution (CC-BY) license (http://creativecommons.org/licenses/by/4.0/). 